\title{
Property Optimisation of EPDM Rubber Composites Using Mathematical and Statistical Strategies
}

\author{
Sivaldo Leite Correia, ${ }^{1}$ Denilso Palaoro, ${ }^{1}$ and Ana Maria Segadães ${ }^{2}$ \\ ${ }^{1}$ State University of Santa Catarina (UDESC), Center of Technology Sciences (CCT), 89223-100 Joinville, SC, Brazil \\ ${ }^{2}$ Department of Materials and Ceramics Engineering (CICECO), University of Aveiro, 3810-193 Aveiro, Portugal \\ Correspondence should be addressed to Ana Maria Segadães; segadaes@ua.pt
}

Received 11 May 2017; Accepted 30 October 2017; Published 21 November 2017

Academic Editor: Francesco Ruffino

Copyright (C) 2017 Sivaldo Leite Correia et al. This is an open access article distributed under the Creative Commons Attribution License, which permits unrestricted use, distribution, and reproduction in any medium, provided the original work is properly cited.

This paper describes a study in which EPDM-based rubber composites were investigated aiming at developing formulations subjected to restrictions on cost and the properties of the material. The contents of components other than calcium carbonate, paraffinic oil, and CBS vulcanising accelerator, as well as additives and processing conditions, were kept constant. Fractional factorial design coupled with computational numerical optimisation was used to minimise the number of mixtures. The results demonstrate that statistical design of experiments and particle swarm optimisation (PSO) algorithms are promising methods to design composition variables. Mixture costs as low as $1.92 \mathrm{US} \$ / \mathrm{kg}$ can be achieved in compositions containing, for example, $107 \mathrm{phr}$ of calcium carbonate, $95 \mathrm{phr}$ of paraffinic oil, and $1.13 \mathrm{phr}$ of CBS accelerator. The corresponding composite propertypredicted values were 66.8 Shore A for hardness, tensile strength of $7.8 \mathrm{MPa}, 570.8 \%$ elongation at break, and $23.0 \%$ rebound resilience. This demonstrates that, in this way, the desired product with specified characteristics can be comfortably manufactured at minimum cost.

\section{Introduction}

The modern rubber industry offers a very wide variety of technological products derived from synthetic elastomers like ethylene-propylene-diene M-class rubber (EPDM rubber). These products find applications in different fields, namely, in automotive, naval, and mechanical industries. Such rubber compounds (composites) are manufactured from complex mixtures of different raw materials (different kinds of EPDM elastomers, fillers, process oil, vulcanising and protecting agents, etc.), and the production steps involve a variety of processes (e.g., mixing, extruding, cutting, moulding, and vulcanising) [1-6].

The performance and manufacture of rubber products has been receiving more and more attention, and the industry has successfully introduced and applied the usage of a series of quality certification standards. Also, stringent market and price competition demand shorter product development cycles and reduced costs, which include raw materials and processing, as well as research and development costs. All of that makes it difficult to define an adequate new formulation by simple adjustment of older ones, based on rule of thumb or virtue of experience.

The application of statistical design of experiments (DoE) to the industrial formulation of rubber composites can be a convenient and accurate means of obtaining reliable quantitative estimates of properties as the result of any change in contents of raw materials $[7,8]$. The modelling of a given property using the design of mixture experiments is becoming common practice [9-17] and was proven, in all cases reported, to lead to greater efficiency and confidence in the results obtained, and to be less demanding in time and both material and human resources.

Many studies on the effects of raw material changes on the physical properties of rubber composites coupled with DoE can be found in the literature, but few data are available on research carried out using the cost characteristics of rubber compounds. However, although standard requirements for physical and mechanical properties of a rubber compound are mandatory, high costs might preclude the product's competitiveness in the market. 
Thus, the rubber compound engineer most often needs to produce an optimised formulation, which fits the requirements of physical and mechanical properties, while subjected to processing and cost constraints [18]. In industrially oriented applications of materials like rubbers or ceramics, the technique generally used to optimise equality and inequality property constraints is the graphical overlay of contour plots generated by the regression models of the properties $[10,15,19-21]$. However, as the number of functions and constraints increases, so do the difficulties to handle and design the different contour plots, and these strategies begin to have a rather limited performance.

Computational optimisation of nonlinear programming problems, which include numerical analysis of continuous and discrete variables, has been an active and important engineering research issue. The optimisation problem consists in finding out a solution for the objective function and related constraints. The use of particle swarm optimisation (PSO) algorithms for solving nonlinear, multimodal, and nondifferentiable optimisation problems, which are not well fitted for conventional optimisation algorithms, has gained increasing attention in recent years [22, 23]. PSO algorithms fundamentals result from the observation, interpretation, and modelling of the movements of individuals in bird flocks or fish schools, as well as their group behaviour as a swarm. It is a simple algorithm, so only a few lines of the computer program based on simple mathematical operations are needed to deploy the basic tool of PSO. The computer-aided optimisation method provides an efficient way to predict the optimum formulation without using those awkward contour plot graphical overlays.

In this work, a fractional factorial design of experiments was used to study the effect of filler, process oil, and vulcanising accelerator contents on the mechanical properties (hardness, tensile strength, elongation at break, and rebound resilience) of EPDM rubber composites. Regression models were calculated from the results of the measured properties, under constant processing conditions and contents of other raw materials and additives. The regression models were then used in a PSO algorithm to obtain optimised EPDM rubber formulations subjected to property constraints and cost requirements.

\section{Experimental Procedure}

2.1. Compound Ingredients and Base Composition. The elastomer used in this work was a commercial M-class ethylene-propylene-diene (EPDM) monomer (Keltan, supplied by Branco Indústria e Comércio Ltda). Other ingredients included carbon black (Spheron 5000, Cabot Brasil Indústria e Comércio), calcium carbonate (Mineração São Judas Ltda), and paraffinic oil (Ipiranga Indústria Quimica Ltda). Besides these ingredients, the mixtures include special additives, namely, vulcanising agent (sulphur, Basile Química), vulcanising accelerator (CBS, N-cyclohexylbenzothiazol-2sulphenamide, Basile Química), vulcanising activator $(\mathrm{ZnO}$, Brazinco Indústria e Comércio), aging inhibitor (Naugard 495, 4-5-methyl-2-mercaptobenzimidazole, Chemtura Indústria Química do Brasil Ltda), and stearic acid (Basile Química).
TABLE 1: Base composition of industrial EPDM rubber composites.

\begin{tabular}{lc}
\hline Ingredients & Content $[\mathrm{phr}]^{\mathrm{a}}$ \\
\hline EPDM & 100.00 \\
Carbon black & 115.00 \\
Calcium carbonate (CC) & Variable \\
Paraffinic oil (PO) & Variable \\
Sulphur, vulcanising agent & 0.40 \\
CBS, vulcanising accelerator (VA) & Variable \\
ZnO, vulcanising activator & 5.00 \\
Naugard 495, aging inhibitor & 1.00 \\
Stearic acid & 1.00 \\
\hline
\end{tabular}

${ }^{a}$ Per hundred of rubber, by weight.

The rubber formulations were based on that of heat- and air-resistant products, such as the automotive hoses manufactured by NSO Borrachas, Joinville, SC, Brazil. As shown in Table 1, the contents (phr, per hundred of rubber, by weight) of calcium carbonate filler (CC), process (paraffinic) oil (PO), and vulcanising accelerator (VA) were varied in the compositions, but the contents of the other raw materials and additives, as well as processing conditions, were kept constant. The chosen processing conditions closely followed the conventional laboratory rubber compound procedure used in industrial practice $[5,6]$.

2.2. Experiment Design. A $3^{3-1}$ fractional factorial design was chosen to model the effect of varying contents of the three factors CC, PO, and VA on the composite properties because it required the minimum number of experiments (nine mixture compositions) for which nonlinear effects and interactions of all the factors could be investigated [7, 8]. Given that the contents of all raw materials and additives other than the three factors were kept constant, a new calculation basis was defined to translate contents of the factors from their usual phr base values, $m_{i}$, into fractions, $X_{i}$, as needed in the factorial design, and vice versa. Among the factors limiting phr values, the CC content is the highest of them all ( $125 \mathrm{phr}$ in the reference product). Hence, this was chosen as the base reference value, $M$, and contents of all the factors were then expressed as weight fraction relative to that of the CC content, that is, $X_{i}=m_{i} / M$. To design the matrix of mixture experiments, three weight fraction content levels were chosen within the usual ranges for the manufacture of general-purpose products, as shown in Table 2.

STATISTICA statistical software (StatSoft Inc., 2010) was used to determine the geometric and coded notations as well as randomise the treatment combinations, resulting in a standard experiment order. Table 3 shows the mixing ratios of chosen factors for the nine compounds, obtained from the $3^{3-1}$ fractional factorial design.

2.3. Mixture Preparation, Moulding, and Property Evaluation. For each of the nine different formulations, in two replications, the selected amounts of raw materials were mixed in a two-roll laboratory mill (Equipabor, Brazil) at $70^{\circ} \mathrm{C}$ and $1: 1.20$ speed ratio, as recommended by the ASTM 
TABLE 2: Factors and levels (weight fraction) adopted for the $3^{3-1}$ fractional factorial design used to define EPDM rubber composites.

\begin{tabular}{lccc}
\hline \multirow{2}{*}{ Factor } & \multicolumn{3}{c}{ Level (weight fraction) } \\
& Low & Medium & High \\
\hline Calcium carbonate (CC) & 0.000 & 0.500 & 1.000 \\
Paraffinic oil (PO) & 0.400 & 0.600 & 0.800 \\
Vulcanising accelerator (VA) & 0.008 & 0.014 & 0.020 \\
\hline
\end{tabular}

TABLE 3: Mixture compositions (weight fractions of chosen factors only) in the $3^{3-1}$ fractional factorial design.

\begin{tabular}{lccc}
\hline Mixture & \multicolumn{3}{c}{ Weight fraction } \\
CO $\left(X_{2}\right)$ & 0.400 & VA $\left(X_{3}\right)$ \\
\hline 1 & 0.000 & 0.600 & 0.008 \\
2 & 0.000 & 0.800 & 0.020 \\
3 & 0.000 & 0.400 & 0.014 \\
4 & 0.500 & 0.600 & 0.020 \\
5 & 0.500 & 0.800 & 0.014 \\
6 & 0.500 & 0.400 & 0.008 \\
7 & 1.000 & 0.600 & 0.014 \\
8 & 1.000 & 0.800 & 0.008 \\
9 & 1.000 & & 0.020 \\
\hline
\end{tabular}

D 15 Standard [24]. The sheets obtained were conditioned at $25 \pm 2^{\circ} \mathrm{C}$ for $24 \mathrm{~h}$ in a sealed container before the estimation of optimum curing time. Batches were then compressionmoulded to a $90 \%$ cure using an electrical resistance heated hydraulic press (model EMIC) at $\sim 10 \mathrm{MPa}$ and $160^{\circ} \mathrm{C}$ during 10 minutes.

The hardness (HD) test was carried out according to ASTM D 676 Standard [25] using a Zwick durometer. The tensile strength (TS) and elongation at break (EB) tests were carried out according to ASTM D 412 Standard [26] using an EMIC DL 2000 testing machine. The rebound resiliency (RS) was determined in accordance with ASTM D2632 using a rebound tester [27]. For each mixture, in each replication, the property final value was taken as the average of the test results obtained for five different test pieces.

2.4. Optimisation Strategy. The experimental results obtained for each property were used to iteratively calculate, with STATISTICA, the coefficients of a regression equation, until a statistically relevant model and response surface was obtained, relating that property value with the weight fractions of calcium carbonate (CC), paraffinic oil (PO), and vulcanising accelerator (VA) present in the corresponding mixture of raw materials.

A PSO algorithm was developed using the property model equations obtained with STATISTICA and common limiting property values (those of the reference automotive hoses manufactured by NSO Borrachas, Joinville, SC, Brazil), aiming at finding the best composition range (weight fractions) that meets the property limits while minimising costs of the composites.

\section{Results and Discussion}

3.1. Measured Properties and Statistical Analysis. Table 4 presents the values of hardness (HD), tensile strength (TS), elongation at break (EB), and rebound resiliency (RS) obtained for the nine mixtures in two replications. Material costs for the nine mixtures in replication 1 are also shown in Table 4.

Table 5 shows the results of the variance analysis of the regression equations obtained for $\mathrm{HD}$, TS, EB, and RS, using the nomenclature commonly found in the literature (major statistical properties: $p$ values and coefficient of multiple determination $R^{2}$ ) [7, 8]. It can be seen that, in all cases, the nonlinear models are statistically significant at the required level ( $p$ value $\leq$ significance level) and present small variability (high coefficients of multiple determination). Although only effects with $p$ value lower than 0.10 were considered significant, $p$ values higher than 0.10 were kept in Table 5 because those effects should appear in the models. In all cases, the errors could be considered randomly distributed around a zero mean value (i.e., they are uncorrelated), which suggests a common constant variance. On the basis of this analysis, the regression models obtained were accepted to describe the effect of contents of raw materials (CC, PO, and VA) on $\mathrm{HD}, \mathrm{TS}, \mathrm{EB}$, and RS, and the final results are (1). These equations are all referred to the weight fractions of the components calcium carbonate $\left(X_{1}\right)$, paraffinic oil $\left(X_{2}\right)$, and vulcanising accelerator $\left(X_{3}\right)$, so that mixing of raw materials can easily be carried out.

$$
\begin{aligned}
\mathrm{HD}= & 91.45-42.13 X_{2}+252.07 X_{3}+10.64 X_{1} X_{2}{ }^{2}, \\
\mathrm{TS}= & 12.39-0.06 X_{1}+1.72 X_{1}{ }^{2}-1.76 X_{2}{ }^{2}-890.02 X_{3}{ }^{2} \\
& -19.51 X_{1} X_{2}+16.22 X_{1} X_{2}{ }^{2} \\
\mathrm{~EB}= & 475.55-56.58 X_{1}-103.51 X_{2}+471.24 X_{2}^{2} \\
& -1040.76 X_{3}-77.94 X_{1} X_{2}^{2}, \\
\mathrm{RS}= & 29.49-4.94 X_{1}-132.57 X_{3}-2.44 X_{1} X_{2}^{2} .
\end{aligned}
$$

3.2. Experimental Validation of the Models. Three extra mixtures, $F_{1}, F_{2}$, and $F_{3}$ (check-point mixtures), were used to validate the calculated statistical models (the mixtures and their test pieces were prepared following the same procedure as before). Table 6 presents the compositions of those three mixtures and the corresponding measured and predicted values for $\mathrm{HD}, \mathrm{TS}, \mathrm{EB}$, and RS. It can be seen that the estimates calculated using (1) can be higher or lower than, but are always very close to, the corresponding experimental value (low error), which validates the calculated models.

3.3. Cost and Property Optimisation Using PSO Algorithm. Following the same procedure and reasoning described above for the compounds mechanical properties, a valid and significant regression model was also obtained for the cost of mixtures (CT), which can be described by the following equation:

$$
\mathrm{CT}=2.68-0.66 X_{1}-0.26 X_{2}+0.28 X_{3} .
$$


TABLE 4: Measured values of hardness (HD), tensile strength (TS), elongation at break (EB), rebound resilience (RS), and material costs (CT) for the nine designed mixtures in two replications.

\begin{tabular}{|c|c|c|c|c|c|c|}
\hline Mixture & & HD (Shore A) & TS (MPa) & EB (\%) & RS (\%) & Cost (US\$/kg) \\
\hline \multirow{9}{*}{ Replication 1} & 1 & $77.0 \pm 0.7$ & $12.5 \pm 0.1$ & $496.7 \pm 08.2$ & $27.8 \pm 1.1$ & 2.63 \\
\hline & 2 & $70.8 \pm 0.5$ & $10.7 \pm 0.2$ & $588.0 \pm 10.9$ & $26.6 \pm 0.6$ & 2.55 \\
\hline & 3 & $59.4 \pm 0.6$ & $11.2 \pm 0.6$ & $670.0 \pm 11.6$ & $26.8 \pm 0.5$ & 2.47 \\
\hline & 4 & $79.0 \pm 0.0$ & $9.5 \pm 0.2$ & $453.3 \pm 10.3$ & $25.0 \pm 0.7$ & 2.22 \\
\hline & 5 & $70.0 \pm 0.7$ & $9.0 \pm 0.2$ & $550.0 \pm 10.0$ & $24.4 \pm 0.6$ & 2.17 \\
\hline & 6 & $61.4 \pm 0.6$ & $8.7 \pm 0.2$ & $636.0 \pm 08.9$ & $26.4 \pm 0.6$ & 2.11 \\
\hline & 7 & $80.8 \pm 0.5$ & $8.1 \pm 0.2$ & $403.3 \pm 08.2$ & $22.6 \pm 0.9$ & 1.91 \\
\hline & 8 & $72.4 \pm 0.9$ & $7.2 \pm 0.2$ & $468.0 \pm 10.9$ & $23.8 \pm 0.5$ & 1.89 \\
\hline & 9 & $65.2 \pm 1.3$ & $7.4 \pm 0.2$ & $565.0 \pm 10.5$ & $24.6 \pm 0.6$ & 1.87 \\
\hline \multirow{9}{*}{ Replication 2} & 1 & $79.8 \pm 0.5$ & $11.6 \pm 1.8$ & $496.6 \pm 08.2$ & $29.6 \pm 0.9$ & - \\
\hline & 2 & $70.8 \pm 0.8$ & $11.8 \pm 0.4$ & $552.0 \pm 10.6$ & $26.0 \pm 0.0$ & - \\
\hline & 3 & $63.4 \pm 0.9$ & $11.1 \pm 0.4$ & $670.0 \pm 11.6$ & $29.0 \pm 1.2$ & - \\
\hline & 4 & $82.4 \pm 1.1$ & $9.3 \pm 0.2$ & $436.0 \pm 08.9$ & $25.2 \pm 1.1$ & - \\
\hline & 5 & $76.4 \pm 0.9$ & $9.6 \pm 0.2$ & $512.5 \pm 09.6$ & $26.2 \pm 0.5$ & - \\
\hline & 6 & $61.2 \pm 0.8$ & $9.0 \pm 0.2$ & $647.5 \pm 09.6$ & $26.6 \pm 0.6$ & - \\
\hline & 7 & $73.0 \pm 0.7$ & $8.8 \pm 0.2$ & $470.0 \pm 11.6$ & $*$ & - \\
\hline & 8 & $73.0 \pm 1.2$ & $7.5 \pm 0.2$ & $486.6 \pm 10.3$ & $25.2 \pm 0.5$ & - \\
\hline & 9 & $75.6 \pm 0.6$ & $7.4 \pm 0.2$ & $566.7 \pm 10.3$ & $22.6 \pm 0.6$ & - \\
\hline
\end{tabular}

${ }^{*}$ Value could not be measured.

TABLE 5: Major statistical properties [7, 8] relevant for variance analysis $\left(R^{2}, p\right.$ value for the significance and lack-of-fit tests) of the calculated regression models $\left(X_{1}\right.$ calcium carbonate, $X_{2}$ paraffinic oil, and $X_{3}$ vulcanising accelerator).

\begin{tabular}{lcccc}
\hline \multirow{2}{*}{ Effect } & \multicolumn{5}{c}{$p$ value* } \\
& HD & TS & EB & RS \\
\hline$X_{1}$ & - & 0.00 & 0.00 & 0.00 \\
$X_{1}^{2}$ & - & 0.07 & - & 0.07 \\
$X_{2}$ & 0.00 & - & 0.00 & - \\
$X_{2}^{2}$ & - & 0.00 & 0.13 & 0.00 \\
$X_{3}$ & 0.06 & 0.10 & 0.12 & 0.10 \\
$X_{3}^{2}$ & - & 0.20 & - & 0.20 \\
$X_{1} X_{2}$ & - & 0.27 & - & 0.27 \\
$X_{1} X_{2}^{2}$ & 0.03 & 0.26 & 0.09 & 0.25 \\
\hline$R^{2}$ & 0.85 & 0.82 & 0.96 & 0.96 \\
\hline Lack-of-fit & 0.99 & 0.89 & 0.77 & 0.55 \\
\hline & ${ }^{*} p$ values of the effects used in the regression models. Other insignificant \\
$p$ values $(>0.10)$ are not presented.
\end{tabular}

In mathematical language, the optimisation problem consists in minimising this objective function (CT) with respect to the design variables $X_{1}, X_{2}$, and $X_{3}$, subjected to the nonlinear inequality constraints posed on HD, TS, $\mathrm{EB}$, and RS, as presented in Table 7 . These property ranges (optimisation goals) were chosen having in mind the standard property specification range commonly required for the heat- and air-resistant products used as reference. From an industrial competitiveness point of view, property values outside (above) that range are not so interesting, as they certainly imply extra cost.

The result of the PSO algorithm procedure (minimum costs) is returned as a composition range (weight fraction) for each of the raw materials CC, PO, and VA. These ranges are also presented in Table 7.
An endless number of mixture composition points can be found which meet the requirements of the properties at low cost values. Alternatively a $2 \mathrm{D}$ graphical visualisation can be used, by keeping constant one of the factors (feasibility curve). In the present case, the CC content was chosen as the base reference value, and contents of all the factors were expressed as weight fraction relative to that CC content. Thus, feasibility curves can be obtained as VA versus PO for various constant CC contents, as shown in Figure 1.

Figure 1 clearly shows that the function describing the infinite number of mixtures with properties within the specified ranges is complex and nonlinear. For a constant CC weight fraction equal to 1.00 , optimised costs vary from 1.82 to $1.87 \mathrm{US} \$ / \mathrm{kg}$, and the PO weight fraction can vary between 0.60 and 0.78 , whereas the VA weight fraction has a much narrower range, varying from 0.008 to 0.009 . Similarly, when the CC level is kept constant at 0.50, the composite costs vary between 2.17 and $2.23 \mathrm{US} \$ / \mathrm{kg}$. The optimum VA weight fraction varies nearly in the same range, but the optimum $\mathrm{PO}$ weight fractions have a different range, in this case from 0.47 to 0.68 . Calcium carbonate at lower levels has a more complex effect on the optimisation and results in higher costs, ranging from 2.53 to $2.58 \mathrm{US} \$ / \mathrm{kg}$. Although the PO weight fraction range is narrower $(0.40$ to 0.60$)$, the VA weight fraction has a broader range, from 0.008 to 0.017 .

Table 8 presents the raw materials' weight fractions and property-predicted values for three illustrative mixtures within the optimum range and shows the corresponding costs, ranging from 1.92 to $2.37 \mathrm{US} \$ / \mathrm{kg}$. From those weight fractions' compositions, the formulations of the corresponding optimised EPDM rubber composites can now be calculated back from the reference CC content (125 phr). The full formulations corresponding to the mixtures in Table 8, meeting the 
TABLE 6: Composition (weight fraction) of the check-point mixtures $F_{1}, F_{2}$, and $F_{3}$ and corresponding measured $(M)$ and predicted $(P)$ values of hardness (HD), tensile strength (TS), elongation at break (EB), and rebound resilience (RS).

\begin{tabular}{|c|c|c|c|c|c|c|}
\hline Wt. fraction & \multicolumn{2}{|c|}{$F_{1}$} & \multicolumn{2}{|c|}{$F_{2}$} & \multicolumn{2}{|c|}{$F_{3}$} \\
\hline$X_{1}(\mathrm{CC})$ & \multicolumn{2}{|c|}{0.303} & \multicolumn{2}{|c|}{0.677} & \multicolumn{2}{|c|}{0.860} \\
\hline$X_{2}(\mathrm{PO})$ & \multicolumn{2}{|c|}{0.438} & \multicolumn{2}{|c|}{0.616} & \multicolumn{2}{|c|}{0.755} \\
\hline$X_{3}(\mathrm{DV})$ & \multicolumn{2}{|c|}{0.008} & \multicolumn{2}{|c|}{0.015} & \multicolumn{2}{|c|}{0.009} \\
\hline Property & $P$ & $M$ & $P$ & $M$ & $P$ & $M$ \\
\hline HD (Shore A) & 68.5 & $69.8 \pm 0.7$ & 76.2 & $78.4 \pm 0.7$ & 69.5 & $70.6 \pm 0.7$ \\
\hline RS (\%) & 26.5 & $27.0 \pm 0.0$ & 25.0 & $25.0 \pm 0.0$ & 24.3 & $24.0 \pm 0.0$ \\
\hline EB (\%) & 585.3 & $668.3 \pm 9.8$ & 470.5 & $522.0 \pm 19.2$ & 551.0 & $526.7 \pm 12.1$ \\
\hline TR (MPa) & 10.47 & $10.10 \pm 0.3$ & 8.92 & $9.32 \pm 0.3$ & 7.65 & $7.43 \pm 0.2$ \\
\hline
\end{tabular}

TABLE 7: Constraint requirements posed on mechanical properties (HD, TS, EB, and RS) and raw materials' (CC, PO, and VA) weight fraction ranges that minimise costs of the composites, as returned by the PSO algorithm.

\begin{tabular}{lccc}
\hline Name & Goal & Lower limit & Upper limit \\
\hline HD (Shore A) & In the range & 65 & 75 \\
TS $(\mathrm{MPa})$ & In the range & 7.5 & 12.5 \\
$\mathrm{~EB}(\%)$ & In the range & 490 & 560 \\
$\mathrm{RS}(\%)$ & In the range & 23 & 28 \\
\hline $\mathrm{CT}(\mathrm{US} \$ / \mathrm{kg})$ & Minimise & - & - \\
\hline$X_{1}(\mathrm{CC})$ & In the range & 0.00 & 1.00 \\
$X_{2}(\mathrm{PO})$ & In the range & 0.40 & 0.80 \\
$X_{3}(\mathrm{VA})$ & In the range & 0.008 & 0.020 \\
\hline
\end{tabular}

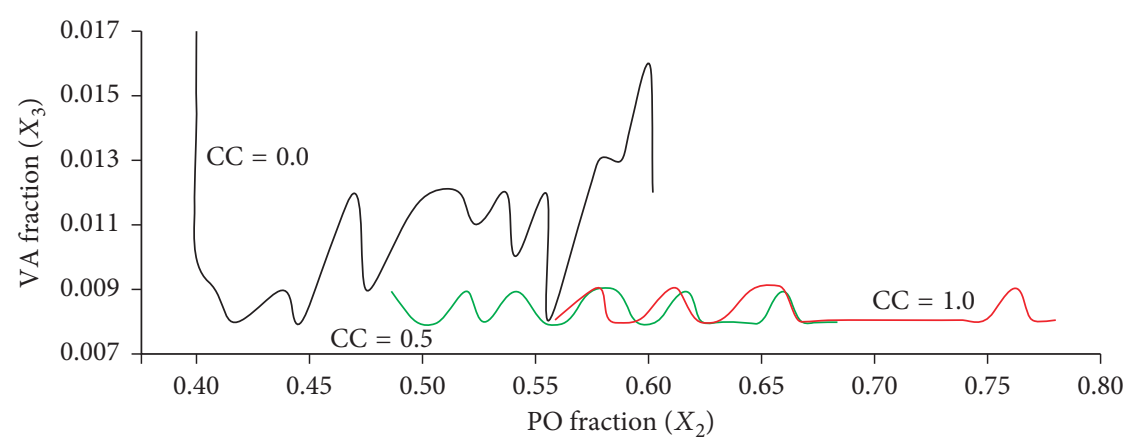

Figure 1: Feasibility curves relating VA and PO weight fractions for optimised cost of composites with properties within the specified ranges, when the CC weight fraction is kept constant at $1.0,0.5$, and 0.0 .

TABLE 8: Examples of optimised mixture compositions and predicted values of the corresponding properties.

\begin{tabular}{lcccccccc}
\hline Mixture point & $X_{1}(\mathrm{CC})$ & $\begin{array}{c}\text { Weight fractions } \\
X_{2}(\mathrm{PO})\end{array}$ & $\begin{array}{c}\text { HD } \\
X_{3}(\mathrm{VA})\end{array}$ & $\begin{array}{c}\text { RS } \\
(\text { Shore A })\end{array}$ & $\begin{array}{c}\text { EB } \\
(\%)\end{array}$ & $\begin{array}{c}\text { TS } \\
(\mathrm{MPa})\end{array}$ & $\begin{array}{c}\text { Cost } \\
(\mathrm{US} \$ / \mathrm{kg})\end{array}$ \\
\hline 1 & 0.860 & 0.755 & 0.009 & 66.8 & 23.0 & 570.8 & 7.8 & 1.92 \\
2 & 0.677 & 0.616 & 0.015 & 72.0 & 23.5 & 516.7 & 8.3 & 2.08 \\
3 & 0.303 & 0.438 & 0.008 & 75.6 & 26.8 & 490.6 & 10.5 & 2.37 \\
\hline
\end{tabular}

requirements of all the mechanical properties, are presented in Table 9.

\section{Conclusions}

This study showed that fractional factorial design of experiments in two replicates based on three mixture ingredients generally used on EPDM rubber composites and a particle swarm optimisation (PSO) algorithm are promising methods to design composition variables.

For the chosen key raw materials (calcium carbonate, paraffinic oil, and CBS vulcanising accelerator) and the processing conditions under consideration, the optimisation results readily show that there is an infinite number 
TABLE 9: Examples of optimised EPDM rubber composites with costs between 1.92 and $2.37 \mathrm{US} \$ / \mathrm{kg}$.

\begin{tabular}{lccc}
\hline Ingredients (phr) & Formulation & Formulation & Formulation \\
& 1 & 2 & 3 \\
\hline EPDM & 100.00 & 100.00 & 100.00 \\
Carbon black & 115.00 & 115.00 & 115.00 \\
$\begin{array}{l}\text { Calcium carbonate } \\
\text { (CC) }\end{array}$ & 107.00 & 85.00 & 38.00 \\
$\begin{array}{l}\text { Paraffinic oil (PO) } \\
\text { Sulphur, vulcanising }\end{array}$ & 95.00 & 77.00 & 55.00 \\
$\begin{array}{l}\text { agent } \\
\text { CBS, vulcanising }\end{array}$ & 0.40 & 0.40 & 0.40 \\
$\begin{array}{l}\text { accelerator (VA) } \\
\text { ZnO, vulcanising }\end{array}$ & 1.13 & 1.88 & 1.00 \\
$\begin{array}{l}\text { activator } \\
\text { Naugard 495, aging } \\
\text { inhibitor }\end{array}$ & 1.00 & 1.00 & 1.00 \\
Stearic acid & 1.00 & 1.00 & 1.00 \\
\hline
\end{tabular}

${ }^{a}$ Per hundred of rubber, by weight.

of compositions that meet specified property values with minimum costs. For example, within the base composition range investigated, mixture costs as low as $1.92 \mathrm{US} \$ / \mathrm{kg}$ can be achieved with the use of $107 \mathrm{phr}$ of calcium carbonate, $95 \mathrm{phr}$ of paraffinic oil, and $1.13 \mathrm{phr}$ of CBS vulcanising accelerator. The predicted values for the corresponding compound properties are 66.8 Shore A for hardness, tensile strength of $7.8 \mathrm{MPa}, 570.8 \%$ elongation at break, and $23.0 \%$ rebound resilience.

In this way, this investigation showed that the specified characteristics of the desired product can be subjected to restrictions typical of the manufacture process, and a broad range of compositions can still be selected so that the final product has minimum cost and can be comfortably manufactured.

\section{Conflicts of Interest}

The authors declare that they have no conflicts of interest.

\section{Acknowledgments}

This research was supported by UDESC-Joinville Project 15085/2011 (Sivaldo Leite Correia). The authors appreciate the financial support received from the Brazilian Research Agencies CNPq (Sivaldo Leite Correia) and CAPES (Denilso Palaoro) and from the Santa Catarina State Research Agency FAPESC (Project 3338/2013) and are thankful to NSO Borrachas Ltda (Joinville-SC, Brazil) for providing the raw materials and access to its laboratories for the development of this work.

\section{References}

[1] P. Tangudom, S. Thongsang, and N. Sombatsompop, "Cure and mechanical properties and abrasive behaviour of natural rubber, styrene-butadiene rubber and their blends reinforced with silica hybrid fillers," Materials \& Design, vol. 53, pp. 856-864, 2014.
[2] E. Demirhan, F. Kandemirli, and M. Kandemirli, "The effects of furnace carbon blacks on the mechanical and the rheological properties of SBR1502 styrene butadiene rubber," Materials \& Design, vol. 28, no. 4, pp. 1326-1329, 2007.

[3] A. Mostafa, A. Abouelk-Kasem, M. R. Bayoumi, and M. G. El-Sebaie, "Effect of carbon black loading on the swelling and compression set behavior of SBR and NBR rubber compounds," Materials \& Design, vol. 30, no. 5, pp. 1561-1568, 2009.

[4] A. Mostafa, A. Abouelk-Kasem, M. R. Bayoumi, and M. G. El-Sebaie, "Insight to the effect of CB loading on tension, compression, hardness and abrasion properties of SBR and NBR filled rubber compounds," Materials \& Design, vol. 30, no. 5, pp. 1785-1791, 2009.

[5] M. Morton, Rubber Technology, American Chemical Society, Van Nostrand Reinhold, New York, NY, USA, 3rd edition, 1987.

[6] C. M. Blow and C. Hepburn, Rubber Technology and Manufacture, Butterworth Scientific, London, UK, 1982.

[7] R. M. Myers and D. C. Montgomery, Response Surface Methodology: Process and Product Optimization Using Designed Experiments, John Wiley \& Sons, New York, NY, USA, 2002.

[8] D. C. Montgomery, Design and Analysis of Experiments, John Wiley \& Sons, New York, NY, USA, 3rd edition, 2001.

[9] H. M. Costa, T. A. S Abrantes, R. C. R. Nunes, L. L. Y. Visconte, and C. R. G. Furtado, "Design and analysis of experiments in silica filled natural rubber compounds-effect of castor oil," Polymer Testing, vol. 22, no. 7, pp. 769-777, 2003.

[10] S. Moonchai and D. Moonchai, "Modelling and optimization of rebound resilience and hardness of defatted rice bran and calcium carbonate-filled NR vulcanisates," Polymer Testing, vol. 32, no. 8, pp. 1472-1478, 2013.

[11] L. Y. Chan, "Optimal designs for experiments with mixtures: a survey," Communications in Statistics-Theory and Methods, vol. 29, no. 9-10, pp. 2281-2312, 2000.

[12] E. K. Nambiar and K. Ramamurthy, "Models relating mixture composition to the density and strength of foam concrete using response surface methodology," Cement and Concrete Composites, vol. 28, no. 9, pp. 752-760, 2006.

[13] S. L. Correia, A. P. N. Oliveira, D. Hotza, and A. M. Segadães, "Properties of triaxial porcelain bodies: interpretation of statistical modelling," Journal of the American Ceramic Society, vol. 89, no. 11, pp. 3356-3365, 2006.

[14] S. L. Correia, G. Dienstmann, M. V. Folgueras, and A. M. Segadães, "Effect of quartz sand replacement by agate rejects in triaxial porcelain," Journal of Hazardous Materials, vol. 163, no. 1, pp. 315-322, 2009.

[15] S. L. Correia, T. Partala, F. C. Loch, and A. M. Segadães, "Factorial design used to model the compressive strength of mortars containing recycled rubber," Composite Structures, vol. 92, no. 9, pp. 2047-2051, 2010.

[16] Y. Cheng, J. Wang, P. G. Jönsson, and Z. Zhao, “Optimization of high-quality vertically aligned $\mathrm{ZnO}$ rod arrays by the response surface methodology," Journal of Alloys and Compounds, vol. 626, pp. 180-188, 2015.

[17] D. Guan, J. H. Wu, and L. Jing, "A statistical method for predicting sound absorbing property of porous metal materials by using quartet structure generation set," Journal of Alloys and Compounds, vol. 626, pp. 29-34, 2015.

[18] B. Cheng, N. Zhu, R. Fan et al., "Computer aided optimum design of rubber recipe using uniform design," Polymer Testing, vol. 21, no. 1, pp. 83-88, 2002. 
[19] M. Balachandran, S. Devanathan, R. Muraleekrishnan, and S. S. Bhagawan, "Optimizing properties of nanoclay-nitrile rubber (NBR) composites using face centred central composite design,” Materials \& Design, vol. 35, pp. 854-862, 2012.

[20] S. L. Correia, D. Hotza, and A. M. Segadães, "Application of mathematical and statistical strategies to optimize ceramic bodies: effects of raw materials on the technological properties," Ceramic Forum International, vol. 82, pp. 39-43, 2005.

[21] S. L. Correia, D. Hotza, and A. M. Segadães, "Simultaneous optimisation of linear firing shrinkage and water absorption of triaxial ceramic bodies using experiments design," Ceramics International, vol. 30, no. 6, pp. 917-922, 2004.

[22] A. Banks, J. Vincent, and C. Anyakoha, "A review of particle swarm optimization. Part I: background and development," Natural Computing, vol. 6, no. 4, pp. 467-484, 2007.

[23] L. Yiqing, Y. Xigang, and L. Yongjian, "An improved PSO algorithm for solving non-convex NLP/MINLP problems with equality constraints," Computers \& Chemical Engineering, vol. 31, no. 3, pp. 153-162, 2007.

[24] ASTM D15, Standard Test Method for Rubber Property. Sample Preparation for Physical Testing of Rubber Products, Annual Book of ASTM Standards, Philadelphia, PA, USA, 1987.

[25] ASTM D676, Standard Test Method for Indentation of Rubber by Means of a Durometer, Annual Book of ASTM Standards, Philadelphia, PA, USA, 1987.

[26] ASTM D412, Standard Test Method for Tension Test of Vulcanized Rubber, Annual Book of ASTM Standards, Philadelphia, PA, USA, 1987.

[27] ASTM D676, Standard Test Method for Rubber PropertyResilience by Vertical Rebound, Annual Book of ASTM Standards, Philadelphia, PA, USA, 1987. 

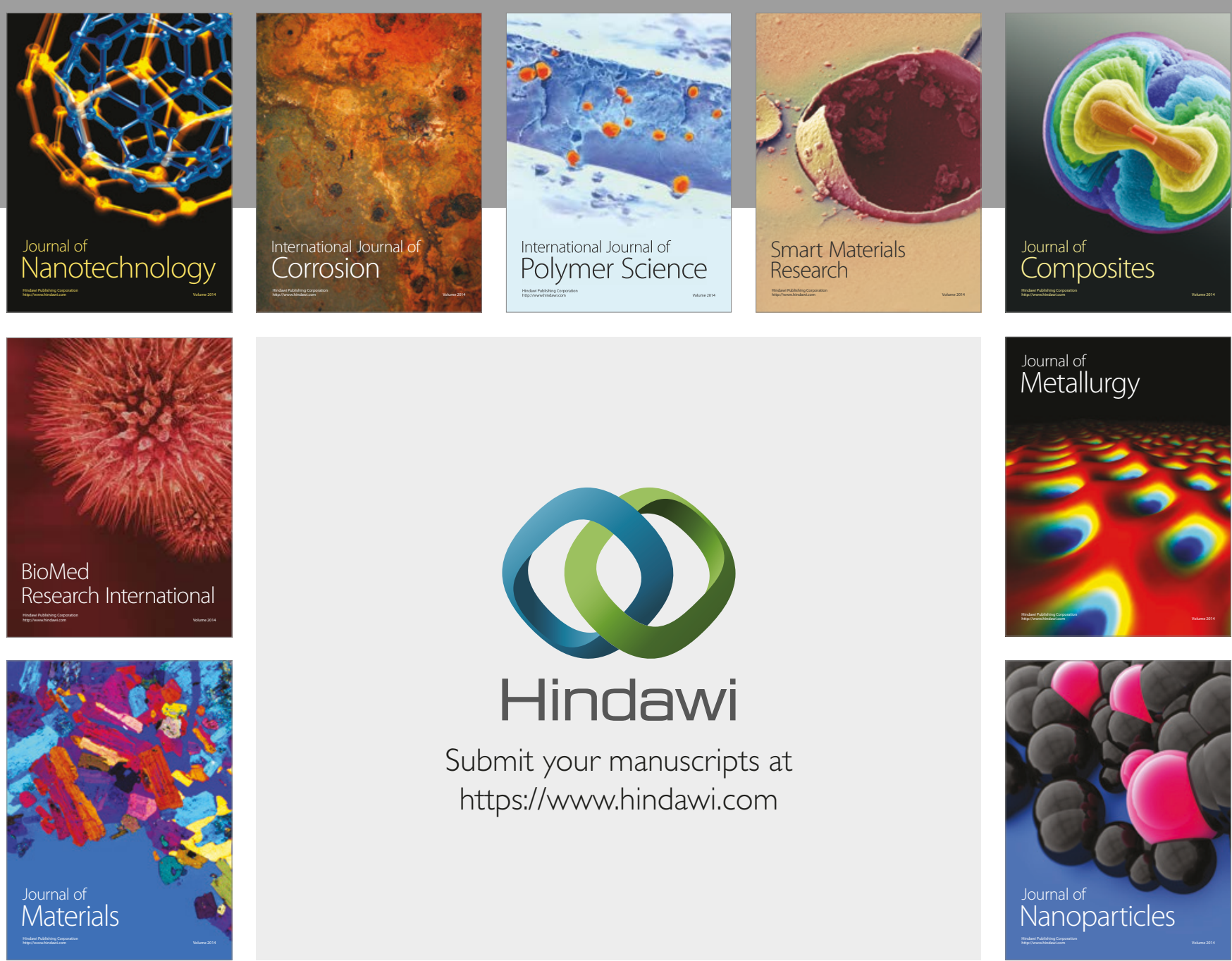

\section{Hindawi}

Submit your manuscripts at

https://www.hindawi.com
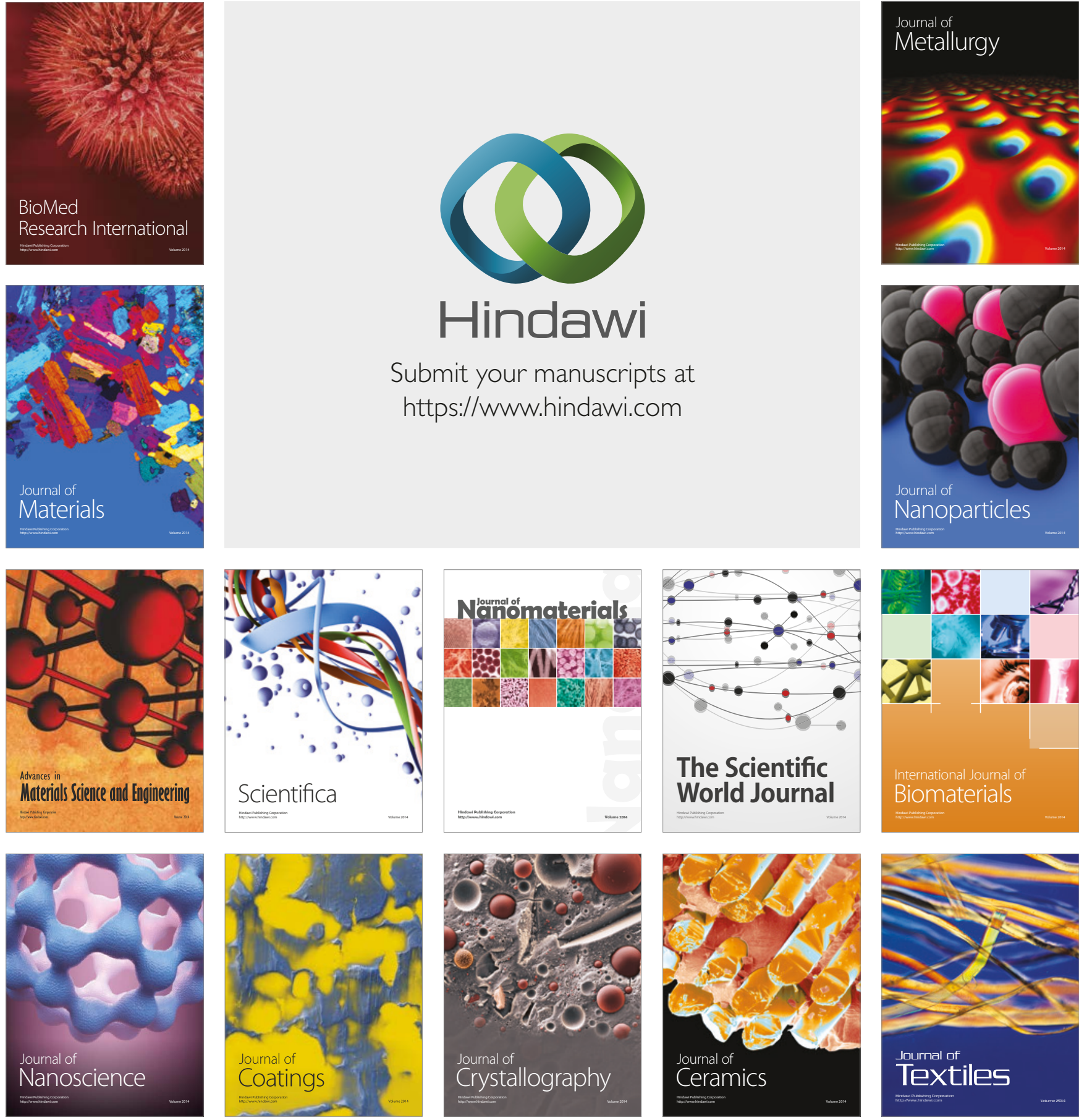

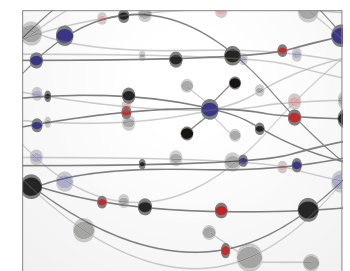

The Scientific World Journal
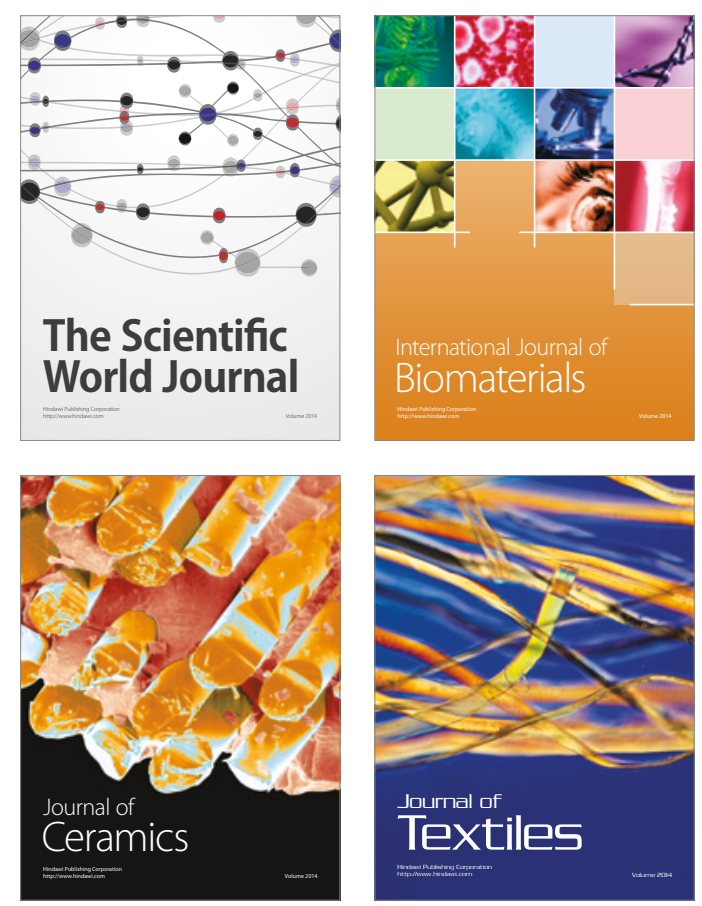